\title{
Perspective on OECD activities from a non-member country
}

\author{
Nevena ALEXANDROVA and Atanas ATANASSOV* \\ Agrobioinstitute, 8, Dragan Tzankov, Sofia 1164, Bulgaria
}

\begin{abstract}
The OECD Blue Book, "Recombinant DNA: Safety Considerations” was published in 1986. The developed principles and concepts on the stepwise and case-by-case approach for risk assessment in the Blue Book have been used as a foundation for building national biosafety frameworks and international instruments for the regulation of the products of modern biotechnology. Twenty years after the Blue Book was published, OECD continues its activities on unique identifier systems, information-sharing, consensus documents for the biology of crops, trees and microorganisms with respect to harmonization of regulatory oversight and those of novel food and feed safety. These activities benefit, without any doubt, the international community at large, including OECD non-member countries. In order to strengthen its position in the international arena and to better respond to the needs of the changing world, OECD would be encouraged to participate in a more active manner in the technology transfer process and co-existence debate, together with continuing the organization's efforts on information-sharing and harmonization in the field of biotechnology and biosafety.
\end{abstract}

Keywords: biosafety / GMOs / technology transfer / developing countries / international organizations / information-sharing

\section{INTRODUCTION}

Since 1980, OECD member countries have worked together on many biotechnology projects, including the publication in 1986 of "Recombinant DNA: Safety Considerations". Also known as the 'Blue Book', this important work dealt with the specific biotechnology of 'genetic engineering', also called genetic modification.

The 1986 Blue Book, the first OECD publication to respond to the 1982 recommendation for safe regulation, put forward key safety concepts for development and commercialization of GMOs, including genetically modified plants for agricultural use. They covered advice on risk assessment; agriculture and the environment; and how to build an understanding of the behavior of the GM plant.

These principles, for instance, on safe small-scale field testing of GM plants, were developed by hundreds of experts from OECD countries, and they have been used as the basis of OECD member countries' GMO regulation.

This set of guidelines today is still the basis of the national regulations in almost all countries that have set up a regulatory framework for agricultural biotechnology.

The experience that OECD has accumulated through the development of these guidelines has allowed the organization to play an active role in the international arena, with a special emphasis on the activities under the Cartagena Protocol on Biosafety. Notwithstanding, today,

*Corresponding author: atanas_atanassov@abi.bg
20 years after the OECD Blue Book was published, some stakeholders have voiced their opinion that the OECD guidelines require fine-tuning, and the position of OECD as a key-player should be reconsidered, in order for the organization to add novel value for the benefit of the international community in this area of controversy.

\section{OECD ACTIVITIES OF BENEFIT TO NON- MEMBER COUNTRIES}

The activities in the field of biosafety that have been undertaken by the OECD, including inter alia the development of the OECD unique identifier for transgenic plants, consensus documents on the biology of the crops and on food safety, databases on field trials and on the products of modern biotechnology, although not initially intended to respond the needs of the third world, have had a significant impact on the development of biosafety frameworks in these countries (Alexandrova et al., 2005).

\section{Unique identifier for transgenic plants}

In February 2002, the OECD published the "Guidance for the Designation of a Unique Identifier for Transgenic Plants". A Unique Identifier is a nine-digit alphanumeric code that is given to each transgenic (or genetically modified) plant that is approved for commercial use, including planting and food/feed use. The guidance has been 
designed so that developers of a new transgenic plant can generate an identifier and include it in the dossiers that they forward to national authorities during the safety assessment process.

The development of this guidance came to eliminate the confusion that could arise during the intergovernmental and inter-institutional information exchange on the same GM crop if different names or descriptions are used for the same product. This is particularly relevant for a scenario in which more and more GM events are approved, and more and more data on their safety becomes available through various sources.

Initially developed to serve the OECD countries, the guidance has been adopted also by other governments and applied in international fora, such as the Cartagena Protocol on Biosafety and the Biosafety Clearing House in particular, which operates under the Protocol.

In January 2004, the EU adopted the OECD guidance as its system for generating unique identifiers. This is found in Commission Regulation (EC) No. 65/2004, "establishing a system for the development and assignment of unique identifiers for genetically modified organisms". At present, all $27 \mathrm{EU}$ member states have adopted this system. With a view of the EU harmonization process, the unique identifier system shall also be applied by the EU candidate countries, most of which are non-member countries for OECD, especially those with enforced legislative framework on GMOs.

The international community would also highly encourage the efforts of OECD on expanding the system of the unique identifier to GM microorganisms and GM animals.

\section{Consensus documents and databases}

Harmonization and coordination of initiatives in biotechnology and biosafety are important driving forces for the activities of international organizations dealing with regulatory aspects, dissemination of information and capacity-building in the context of protecting the environment and human health from products of modern biotechnology. This need for harmonization and coordination is mainly due to different strategies and standards adopted at the national level, and different infrastructures in place in developed and developing countries.

The OECD was one of the first international organizations to have promoted the attempt for harmonization at the level of regulation of the products of modern biotechnology to ensure that the environmental protection and safety aspects are properly addressed. This was done through the programs: The Harmonization of Regulatory Oversight in Biotechnology and Safety of Novel Foods and Feeds established in 1997-1999. The major component of these programs is the development of consen- sus documents, which provide common information for environmental risk/safety assessment. These consensus documents comprise technical information for use during the regulatory assessment of products of biotechnology and are intended to be mutually recognized among the OECD member countries. They either focus on the biology of organisms (such as plants, trees or microorganisms) or introduced novel traits. At present there are over 40 consensus documents available, which encompass crops with economic relevance not only for the OECD member states but also for non-member countries (e.g. consensus document on the biology of Papaya). With this respect and from the harmonization perspective, OECD would be highly encouraged to continue the work on species with high socio-economic value for the developing countries and countries with economies in transition. To reach this aim, the involvement of more experts, especially from the countries that are centers of origin of biodiversity, such as the Balkan region for instance, should be better represented at the OECD task forces' meetings.

The consensus documents elaborated in the frame of the program Safety of Novel Foods and Feeds are science-based and contain data for use during the regulatory assessment of a particular food or feed product. In the area of food and feed safety, overall 14 consensus documents have been published on the nutrients, antinutrients or toxicants, information of the product's use as a food/feed and other relevant information.

Another relevant initiative in these programs is the development of OECD's online databases of (i) products of biotechnology (http://www.olis.oecd.org/bioprod.nsf) and (ii) field trials (BioTrack) (http://www.olis.oecd.org/biotrack.nsf), which include records of GMO field trials that have taken place in OECD member countries, as well as data from other countries provided through UNIDO's Biosafety Information Network and Advisory Service (BINAS) (Degrassi et al., 2003).

\section{OECD ACTIVITIES OF BENEFIT TO NON- MEMBER COUNTRIES - REGIONAL ASPECTS}

The efforts for harmonization of regulatory oversight in biotechnology and the cutting-edge issues of the food and feed safety of novel products (including GM food and feedstuffs) that have been taken on by OECD in the international arena, as well as the Organization's specific activities on the elaboration of science-based consensus documents and databases, have influenced five countries in the Black Sea region, which established in June 2004 the Black Sea Biotechnology Association (BSBA) as an international public non-profit organization. Its mandate 
is to promote the science-based approach in all levels of decision-making process, thus acting as guarantee for the informed choice of the consumers and the general public, while avoiding unnecessary barriers to trade, within the region and globally.

BSBA member countries so far are Bulgaria, Romania, Russia, Turkey and Ukraine, while Serbia and Georgia have the status of associate and candidate members respectively. BSBA is governed by a Board of Directors in consultations with its Board of Trustees.

The goals of BSBA are to:

- create within the Black Sea region, a network of countries with historically similar agricultural needs, priorities and often practices, science-based regulations that not only protect the public health and the regional environment, but also stimulate economic development, international trade, modern agricultural practices, modern food and feed production industry, east/west collaborations and the advancement of regional varieties;

- increase the region's contribution to and participation in the global debate regarding agricultural biotechnology;

- avoid regulatory and trade practices for agricultural biotechnology that lead to unnecessary and/or unjustified barriers that encumber commerce and ultimately disadvantage the region; build a system of mutual recognition of regulatory and safety data for agricultural products improved through biotechnology;

- build regional human and organizational (including information sharing) capacity to understand and responsibly employ agricultural biotechnology;

- contribute to public perception of biotechnology by setting facts against factoids;

- networking the local decision-makers, research institutions and other stakeholders of the region;

- launch the regional Biotechnology Information Center which will work in cooperation with other information networks and serve in real time mode as the regional agricultural biotechnology clearing house;

- launch the annual Black Sea Region Biotech Forum. At the Forum, regulatory, economic development and trade related issues of agricultural biotechnology will be discussed and solutions proposed for the countries surrounding the Black Sea region in areas of technology, seed and commodities.

To fulfill these goals, BSBA is active through a regional biotechnology web portal that works in cooperation with other information networks, and serves in real time mode as the regional agricultural biotechnology clearing house (http://www.bsbanet.org/).

Another permanent BSBA activity is the venue of an Annual Black Sea Region Biotech Forum - a platform for regulatory, economic development and trade related issues of agricultural biotechnology.

Inspired by the concept and the work done by OECD on the consensus documents both on the biology of the crops, and food and feed safety of novel products, including products from modern biotechnology and consistent with its mandate, BSBA recently finalized consensus documents on environmental risk assessment of three crops, resulting after a genetic modification - GM maize, GM soybean, GM sugar beet. Each of these crops has a significant share in the BSBA countries' agriculture and economies. The documents summarize the regional research experience accumulated after controlled (GM maize, GM sugar beet) or commercial releases in the countries from the Black Sea region (Atanassov et al., 2003; Rosca, 2004), and are meant to facilitate the risk assessment, risk management and the overall process of event-specific decision-making.

In addition to its activities, the BSBA is also establishing a regional network of laboratories to work on mutually and internationally adopted and available validated detection, identification and monitoring methods and procedures on GMOs. This regional GMO network of laboratories would work in close cooperation with the European Network of GMO labs (ENGL), of which two of the BSBA countries - Bulgaria and Romania, are members.

It is appropriate to mention that the OECD assists BSBA at all levels by participation of one of the organization's representatives on the BSBA Board of Trustees.

\section{CONCLUSIONS AND RECOMMENDATIONS FOR FUTURE OECD ACTIVITIES INVOLVING NON- MEMBER COUNTRIES}

Six years after the OECD Blue Book was published in 1986, the countries participating in the Earth Summit (1992) have agreed upon the fact that biotechnology can offer indubitable benefits to sustainable development, world food supplies and economic prosperity. In order for this potential to be largely applied worldwide, and with particular emphasis in developing countries, and thus facilitating the alleviation of poverty, the countries joined their efforts in preparation of international rules. These would both ensure the further development of biotechnology for the benefit of the society at large, and the conservation of genetic resources, especially in the centers of origin (mostly situated in the third world). The international rules, reflected both in the Cartagena Protocol on Biosafety and the WTO agreements, are built on a scientific basis, and promote the principle of the case-by-case approach, first set in the OECD Blue Book. According to this principle, every transgenic event should undergo a separate risk assessment, and potential hazards specific to 
this event should be identified, and specific risk management measures assigned. The case-by-case approach is now commonly applied in the national legislation frameworks on biosafety in the countries where they are in place (Alexandrova et al., 2005)

Twenty years after the Blue Book, fourteen years after the Earth Summit and Agenda 21, and twelve years after the first GM product, the Flavr Savr tomato, reached the market, the issue of the use and sustainable management of the products of modern biotechnology is still ongoing and has even gained in controversy in the public debate. This is particularly valid for the developing countries and the countries with economies in transition, which, instead of getting the full benefits of the GM technology, voice concerns about its application within their particular environments.

Notwithstanding the efforts taken by OECD, which have been highly appreciated so far, including by the OECD non-member countries, it would be recommendable for the Organization to address in a more active manner the considerations of the developing world, i.e. by strengthening North-South, as well as West-East collaboration.

In this respect, many countries need to acquire the technology and the capacities necessary to handle the results of modern biotechnology in a sustainable manner (Altman, 1993). Therefore, public awareness, education and technology transfer play an important role. Intellectual Property Rights issues and technology transfer in the field of modern biotechnology require, however, deeper attention. Several reasons can be offered, among which the facts that:

- currently the multinational biotech companies are the holders of the IPRs of most of the transgenes that have been commercially introduced (Falcon, 2001);

- these transgenes are introduced into few varieties or hybrids that although promising in the conditions of intensive cultivation in North America, are, in general not specifically designed to be adapted to different climatic conditions (e.g. Africa, Asia, the Balkans). Thus growers, especially poor farmers, risk potentially greater yield loss if they use these GM varieties, instead of sticking to the conventional ones (Bhatia, 2001);

- a growing concern exists that the newly introduced $\mathrm{GM}$ varieties, if able to demonstrate clear benefits and increase income, would gain market share, and as a consequence restrict the local agrobiodiversity (Srinivasan and Thirtle, 2000).

The solution can be identified within the technology transfer by introducing the genes, a company property, into local traditional varieties, together with promoting equal share of the IPRs between multinational companies and local research centers/breeders. In this respect, the OECD is in a unique position to play the role of a mediator between its member countries (biotech exporters) and non-member countries (biotechnology importers) in this technology transfer dialogue.

In addition, OECD is in the position to initiate activities and to play a role in the co-existence debate, due to the fact that co-existence of conventional, organic and GM production systems is both an agricultural and economic issue, and as such falls within the scope of the Organization. Co-existence is also a growing issue in many OECD member countries (e.g. EU), and it is a topic of concern for most of the non-member countries (Bock et al. 2002; Brookes and Barfoot, 2003a, 2003b, 2004; Alexandrova and Atanassov, 2005).

It is commonly understood that international and regional harmonization, in addition to synchronizing the national regulatory frameworks, should focus on the issues of strengthening capacities and information sharing in the field of safety in biotechnology. During the last twenty years, OECD has been very active in this respect, and has demonstrated that the Organization was playing a key role in collaboration with a number of international organizations such as FAO, WHO, UNEP, UNIDO, OECD, ICGEB and CGIAR. These organizations, together with the cooperation of regional associations (i.e. BSBA), are in the position to offer necessary assistance in capacity-building and dissemination of information on biosafety.

\section{REFERENCES}

Alexandrova N, Atanassov A (2005) Co-existence of conventional and organic farming with GMO-based agriculture in Bulgaria. GMCC-05, Montpellier

Alexandrova N, Georgieva K, Atanassov A (2005) Biosafety regulations of GMOs: national and international aspects and regional cooperation. Biotechnol. Biotechnol. Eq. 19: 153172

Altman DW (1993) Plant biotechnology transfer to developing countries. Curr. Opin. Biotechnol. 4: 177-179

Atanassov A, Georgieva K, Koleva L, Yankulova M, Cherkesova S, Dimitrov S (2003) Final report on the sixyear activity (1998-2003) of the Council on safe work with genetically modified higher plants, established to the Ministry of Agriculture and Forestry. Biosafety newletters, Diagnosis Press

Bhatia CR (2001) Bt cotton in India. Current Sci. 80: 321-322

Bock AK, Lheureux K, Libeau-Dulos M, Nilsgard H, Rodrigez-Cerezo E (2002) Scenarios for co-existence of genetically modified, conventional and organic crops in European agriculture. European Commission, Joint Research Center 
Brookes G, Barfoot P (2003a) Co-existence of GM and non GM arable crops: case study of the UK. PG Economics Ltd.

Brookes G, Barfoot P (2003b) Co-existence of GM and non GM crops: case study of maize grown in Spain. PG Economics Ltd.

Brookes G, Barfoot P (2004) Co-existence in North American agriculture: can GM crops be grown with conventional and organic crops? PG Economics Ltd.

Degrassi G, Alexandrova N, Ripandelli D (2003) Review: Databases on biosafety of GMOs. Environ. Biosafety Res. 2: 145-160
Falcon WP (2001) Globalizing germ plasm: barriers, benefits and boundaries. Tomorrow's agriculture: incentives, institutions, infrastructure and innovations. Proceedings of the 24th International Conference of Agricultural Economists, Berlin

Rosca II (2004) Impact of genetically modified herbicide resistant maize on the arthropod fauna. Bulletin OILB/SROP 27 : $143-146$

Srinivasan CS, Thirtle C (2000) Policy arena: genetically modified organisms and smallholders in the developing world. J. Int. Dev. 12: 1131-1132 